\title{
Biosynthesis of Iron Nanoparticles from Pleurotus florida and its Antimicrobial Activity against Selected Human Pathogens
}

\author{
G. MANIKANDAN ${ }^{1 *}$ AND R. RAMASUBBU
}

Department of Biology, The Gandhigram Rural Institute (Deemed to be University) Dindigul, Tamil Nadu-624001, ${ }^{1}$ Department of Botany, Sri Kaliswari College (Autonomous), Sivakasi, Tamil Nadu-626123, India

\section{Manikandan et al.: Biosynthesis of Iron Nanoparticles from Mushroom Extract}

\begin{abstract}
In the present investigation, iron nanoparticles were synthesized by using mushroom extract. The production of iron nanoparticles from Pleurotus florida was initially confirmed by color changes from brown to dark brown within $30 \mathrm{~min}$ at $60^{\circ}$ and further characterized by Ultraviolet-Visible spectroscopy and scanning electron microscope with Edax. The biosynthesized iron nanoparticles were subjected to antimicrobial activities and showed higher zone of inhibition against Candida glabrata followed by Micrococcus mucilaginosus, Pseudomonas aeruginosa, Candida albicans, Klebsiella terrigena, Klebsiella pneumoniae, Escherichia coli, Candida sp., Bacillus cereus and Staphylococcus aureus. This extract was confirmed as effective against microorganisms which was well comparable with standard antibiotics. The present study has recommended that iron nanoparticles from mushrooms have great potential to act as safe alternative to antibiotics to fight the challenges of drug discovery.
\end{abstract}

Key words: Pleurotus florida, iron nanoparticles, ultraviolet-visible spectroscopy, scanning electron microscope, antimicrobial

Nanotechnology provides the tools and technology platform for the investigation and transformation of biological systems and biology offers inspiration models and bio-assembled components to nanotechnology. Nano biotechnology is a field that applies the nanoscale principle and techniques to understand and transform biosystems (living and non -living) which uses biological principles and materials to create new devices and systems integrated from the nanoscale ${ }^{[1]}$. Nanotechnology has dynamically developed as an important field of modern research with potential effects in electronic and medicine ${ }^{[2,3,4]}$. Nanobiotechnology combines biological principles with physical and chemical procedures to generate nano-sized particles with specific functions. Nanobiotechnology represents an economic alternative for chemical and physical methods of nanoparticles formation. These methods of synthesis can be divided on intra cellular and extracellular ${ }^{[5]}$.

Iron is an essential element which involved in synthesis of many important cell components such as adenine triphosphate (ATP), transport of oxygen, deoxyribonucleic

*Address for correspondence

E-mail: rgmani.19@gmail.com

January-February 2021 acid (DNA) and electron transport. In human, iron is a component of hemoglobin and myoglobin but when it is low in supply, it leads to nutritional deficiency called, anemia. Anemia is one of the major public health problems in under-developing and developing countries, particularly among pregnant women, nursing mothers and the newborn babies. Iron is also one of the most abundant metals on the earth but it is not readily available. Although, most of the microbes have developed various regulated system for iron uptake, utilization and storage but some food crops show low absorption capability for iron. The diminishing quantity of iron in food has tremendously contributed to increase in malnutrition which therefore required a reliable and alternative source of iron supply in foods to enhance the promotion of good health ${ }^{[6]}$.

\footnotetext{
This is an open access article distributed under the terms of the Creative Commons Attribution-NonCommercial-ShareAlike 3.0 License, which allows others to remix, tweak, and build upon the work non-commercially, as long as the author is credited and the new creations are licensed under the identical terms
}

Accepted 16 February 2021

Revised 24 October 2020

Received 31 July 2020 Indian J Pharm Sci 2021;83(1):45-51 
Iron oxide nanoparticles have attracted intensive research interest because of their important applications in cancer therapy, drug delivery, magnetic resonance imaging (MRI) and waste water treatment. The biosynthesis of iron oxide nanoparticles of different sizes and shapes has been reported using bacteria, fungi and plant extract. The bioreduction of metal by combinations of biomolecules found in plant extract, resulting in the formation of metal nanoparticles has been extensively reviewed ${ }^{[7]}$. The synthesis of nanoparticles using plant extract could be advantageous over other biological processes since it eliminates the elaborate process of maintaining cell cultures.

In recent years, novel size-dependent physicochemical properties have led to metallic iron nanoparticles of great potential in a wide range of applications, including magnetic storage media ${ }^{[8]}$, ferrofluids, biosensors, catalysts, separation processes and environmental remediation ${ }^{[9]}$. Specifically, magnetite $\left(\mathrm{Fe}_{3} \mathrm{O}_{4}\right)$ is a common magnetic iron oxide having a cubic inverse spinel structure. The compound exhibits unique electric and magnetic properties based upon the transfer of electrons between $\mathrm{Fe}^{2+}$ and $\mathrm{Fe}^{3+}$ in octahedral sites.

For a long time in Asian countries, a variety of edible mushroom have been taken as vitamin and mineral supplements. Studies on edible mushroom have revealed, valuable activities related to biological response modification. Chemo-preventative, chemotherapeutic, immune modulatory, hypoglycemic and hypocholesterolemic effects have been observed in edible mushroom diets high in mushrooms were reported. Suppress the enzyme aromatase and the active antitumor material was suggested to be a polysaccharide ${ }^{[10]}$. Mushrooms have variety of bioactive compounds with various biological activities. The content and bioactivity of these compounds depend on the preparation and consumption of mushroom. It is well known that mushrooms are rich in proteins, vitamins and amino acids. Edible mushrooms have antitumor, anti-inflammatory, cardiovascular, antiviral and antibacterial activities ${ }^{[11,12]}$. Several mushrooms are used for medicinal purposes which accumulate a variety of secondary metabolites including rich sources of beta glucan, proteoglucan, lectin, phenolic compounds, flavonoids, triterpenoids, dietary fiber, leutinan, steroids, glycopeptides, terpenes, saponin and phenolic compounds. All the reported compounds have high therapeutic values and promote health being as agent with antioxidant, antimicrobial, cholesterol lowering and immune stimulatory effect, antifungal and antitumor properties. The synthesis of iron nanoparticles from mushroom and production of new dietary supplements and new pharmaceutical products have been exploited. This study has attempted synthesize bionanoparticles using oyster mushroom and analyzed their antibacterial and antifungal properties. The confluence of nanotechnology and biology could address several biomedical, health and medicine.

\section{MATERIALS AND METHODS}

\section{Collection and preparation of mushroom extracts:}

The fruiting bodies of Pleurotus florida were collected from the local market, Chinnalapatti, Dindigul, Tamil Nadu, India. The collected mushrooms were thoroughly washed with tap water and finely cut (1 inch size) and again washed with distilled water. A total of $20 \mathrm{~g}$ of fresh mushrooms were added to $100 \mathrm{ml}$ of deionised water and warmed for one hour in a water bath at $60^{\circ}$ and filtered through Whatman No. 1 filter paper. The extracts were stored at $4^{\circ} \mathrm{C}$ for further experiments fig. $1 \mathrm{~A}$.

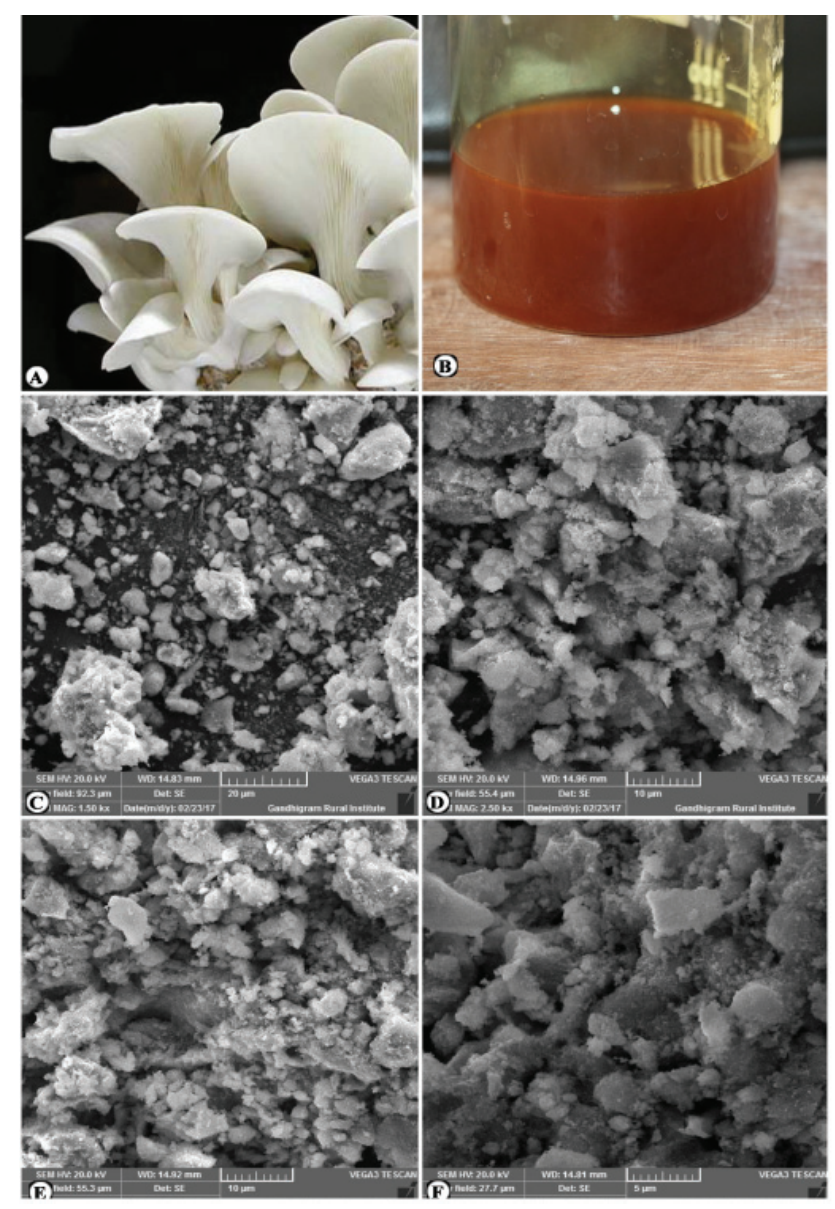

Fig. 1 A: Pleurotus florida; B: Synthesized iron nanoparticles from Pleurotus florida, C-F: SEM images of synthesized iron nanoparticles from Pleurotus florida 


\section{Biosynthesis and characterization of iron nanoparticles:}

A total of $50 \mathrm{ml}$ of mushroom extracts was added to $50 \mathrm{ml}$ of $1 \mathrm{M}$ Ferric Chloride in 1:1 proportion at a temperature of about $50-60^{\circ}$ and the solution was stirred continuously. The color change from brown to dark red was noticed and formation dark brown color after certain time period has indicated the formation of iron nanoparticles fig. 1B. After that, the synthesized extracts were centrifuged at 3000-5000 rpm for $15 \mathrm{~min}$ and washed with double distilled water thrice and collected the pellet dried by using hot air oven and stored for further characterization.

The characterization of synthesized iron nanoparticles was carried out by Ultraviolet Visible (UV-VIS) absorption spectrophotometer and Scanning Electron Microscopy (SEM). Synthesized extracts of $0.3 \mathrm{ml}$ of iron nanoparticle solution were diluted in $3 \mathrm{ml}$ distilled water. UV-VIS spectroscopy analysis was carried out on a Jasco v 530, UV-VIS absorption spectrophotometer with a resolution of $2.0 \mathrm{~nm}$ between 200 to $800 \mathrm{~nm}$ possessing a scanning speeds of $300 \mathrm{~nm}$ per min. The process of reaction between metal ions and biosynthesis of iron nanoparticle was monitored by UV-VIS spectra of iron nanoparticles in aqueous solution. Synthesized extracts were centrifuged at 3000-5000 rpm for $15 \mathrm{~min}$ and washed with double distilled water thrice and collected the pellet. The pellet was dried by using hot air oven and stored for further characterization. For SEM, analysis the Iron nanoparticle synthesized by using mushroom was allowed to dry completely and ground well to a powder specimen. Since, the specimen needs to be at high vacuum, fixation was usually performed by incubation in a solution of a buffered chemical fixative, such as glutaraldehyde. The dry specimen was mounted on using an adhesive epoxy resin of electrically conductive double sided adhesive tape and sputter coated with gold palladium alloy before examination in the microscope. The powdered samples were coated with gold $(20 \mathrm{~mm})$ palladium in a SCD 020 sputter coating machine and observed in a Tescan Vega 3, SEM at Central Instrumentation facility, The Gandhigram Rural Institute (Deemed to be University), Gandhigram, Dindigul, Tamil Nadu.

\section{Determination of antimicrobial activities:}

The microorganisms used for the study were collected from the co-culture collections of laboratory of Department of Biology, Gandhigram Rural Institute (Deemed to be University), Gandhigram, Dindigul. Gram-positive bacteria; Bacillus cereus, Staphylococcus aureus and Micrococcus mucilaginosus, gram-negative bacteria; Klebsiella pneumoniae, K. terrigena, Pseudomonas aeruginosa, Escherichia coli and Fungi; Candida albicans, C. glabrata and Candida sp. were used for the study (Table 1). The bacterial and fungal strains were maintained in nutrient agar medium. The strains were subcultured bimonthly and the cultured strains were allowed to grow for one week and stored at $5^{\circ}$ for further analysis.

The iron nanoparticles synthesized using mushroom extracts were tested for antibacterial activity by agar well-diffusion method against various pathogenic gram-positive bacteria; Bacillus cereus, Staphylococcus aureus and Micrococcus mucilaginosus, gram-negative bacteria; Klebsiella pneumoniae, $K$. terrigena, Pseudomonas aeruginosa, Escherichia coli and Fungi; Candida albicans, C. glabrata and Candida sp. Nutrient agar (NA) plates were spread with the help of L-rod inside the laminar air flow chamber with $8 \mathrm{~h}$ old broth culture of respective bacteria and fungi. The wells with $6 \mathrm{~mm}$ diameter and about $2 \mathrm{~cm}$ a part were made in a medium of petriplate each using sterile cork borer. Mushroom nanoparticle sample was prepared at a different concentration $(100,150$ and $200 \mathrm{mg} / \mathrm{ml}$ and added with the help of micropipette into the wells and

TABLE 1: STANDARD MICROBIAL STRAINS USED FOR SCREENING OF ANTIMICROBIAL ACTIVITIES OF PLEUROTUS FLORIDA IRON NANOPARTICLES

\begin{tabular}{lccc}
\hline S.No & Name of the microbial strain & Grams nature & Strain No. \\
\hline 1 & Bacillus cereus & Gram-positive bacteria & GRIBIO1 \\
2 & Staphylococcus aureus & Gram-positive bacteria & GRIBIO5 \\
3 & Micrococcus mucilaginosus & Gram-positive bacteria & GRIBIO8 \\
4 & Klebsiella pneumoniae & Gram-negative bacteria & GRIBIO2 \\
5 & Pseudomonas aeruginosa & Gram-negative bacteria & GRIBIO4 \\
6 & Escherichia coli & Gram-negative bacteria & GRIBIO6 \\
7 & Klebsiella terrigena & Gram-negative bacteria & GRIBIO9 \\
8 & Candida albicans & Fungi & GRIBIO3 \\
9 & Candida glabrata & Fungi & GRIBIO7 \\
10 & Candida sp. & Fungi & GRIBIO10 \\
\hline
\end{tabular}


allowed to diffuse at room temperature for $2 \mathrm{~h}$. Standard antibiotic, Ampicillin (both bacteria and fungi) was (100 $\mathrm{mg} / \mathrm{ml}$ ) selected to serve as positive control. Control experiments comprising inoculums without mushroom nanoparticle sample were set up and the plates were incubated at $37^{\circ}$ for $18-24 \mathrm{~h}$ for bacterial pathogens and $28^{\circ}$ for $48 \mathrm{~h}$ for fungal pathogens ${ }^{[13,14,15]}$. The diameter of the inhibition zone ( $\mathrm{mm}$ ) was measured by Antibiotic scale and the activity index was also calculated for triplicates of each experiment.

\section{RESULTS AND DISCUSSION}

Different concentration of $1 \mathrm{M}$ Ferric chloride solutions $(10 \mathrm{ml}-50 \mathrm{ml})$ were prepared and $P$. florida extract were added $(50 \mathrm{ml})$. After adding the mushroom extracts with Ferric chloride solution, the colour of the solution has turned from brown to dark brown which indicated the formation of iron nanoparticles in 1:1 ratio. The synthesized iron nanoparticle extracts were centrifuged at 3000-5000 rpm for 15 min and washed with double distilled water thrice and collected the pellet. The pellet was dried by using hot air oven and stored for further characterization.

Synthesized extracts of $0.3 \mathrm{ml}$ of iron nanoparticle solution was diluted into $3 \mathrm{ml}$ by distilled water. UVVIS spectral analysis was done by using UV-VIS spectrophotometer Systronics 118 at the range of 200-800 $\mathrm{nm}$. The intensity of peak with respect to the height, increased gradually with increase of time. It was observed from the spectra that the iron surface plasma band occurs at $270 \mathrm{~nm}$. It is well known that, the size and shape of iron nanoparticles reflect the absorption peak. The position of the peak strongly depends on the shape and size of the nanoparticles in association with other parameters which are identical to the characteristics of UV VIS spectrum of metallic iron and it was recorded (fig. 2).

SEM technique was employed to visualize the size and morphology of nanoparticles. Most of the iron nanoparticles were spherical in shape. A few agglomerated iron nanoparticles were also observed in some places. The morphology and the particle size of iron nanoparticles were determined by using SEM micrography. Synthesized nanoparticles were spherical in size and roughly with $100 \mathrm{~nm}$. Morphological studies of the synthesized iron nanoparticles were carried out by using fitted with an Energy Dispersive Spectrophotometer (EDS) (fig. 1C-F \& fig. 3).

The sample was observed at $10000 \mathrm{X}$ magnification with an accelerating voltage of $20 \mathrm{kV}$. The energy dispersive X-ray analysis (EDX) revealed strong signal in the maximum percentage $(87.57 \%)$ of iron $(\mathrm{Fe})$ region was found in synthesized powder sample and it was confirmed with the formation of iron nanoparticles. The other peak for Chlorine (2.42\%), Sodium (3.20\%) and Oxygen (6.81\%) in $\mathrm{Fe}$ is due to the precursors of iron nanoparticles (fig. 3).

The iron nanoparticles synthesized using mushroom extracts were tested for antimicrobial activity by agar well-diffusion method against various pathogenic gram-positive bacteria; Bacillus cereus, Staphylococcus aureus and Micrococcus mucilaginosus, gram-negative bacteria; Klebsiella pneumoniae, $K$. terrigena, Pseudomonas aeruginosa, Escherichia coli and Fungi; Candida albicans, C. glabrata and Candida sp. and the zone of inhibition was measured in mille meter ( $\mathrm{mm}$ ). In addition, the inhibition zones formed by standard antibiotics (Amphicillin) and those of negative controls were recorded. Among these different concentrations $(100 \mu \mathrm{g} / \mathrm{ml}, 150 \mu \mathrm{g} / \mathrm{ml}$ and $200 \mu \mathrm{g} / \mathrm{ml})$, the iron nanoparticles of $P$. florida were exhibited antimicrobial activity against all the selected microorganisms. The clear inhibition zones were found at $24 \mathrm{~h}$ after incubation at $37^{\circ}$.

The iron nanoparticles of Pleurotus florida showed strong inhibition $(200 \mu \mathrm{g} / \mathrm{ml})$ against Candida

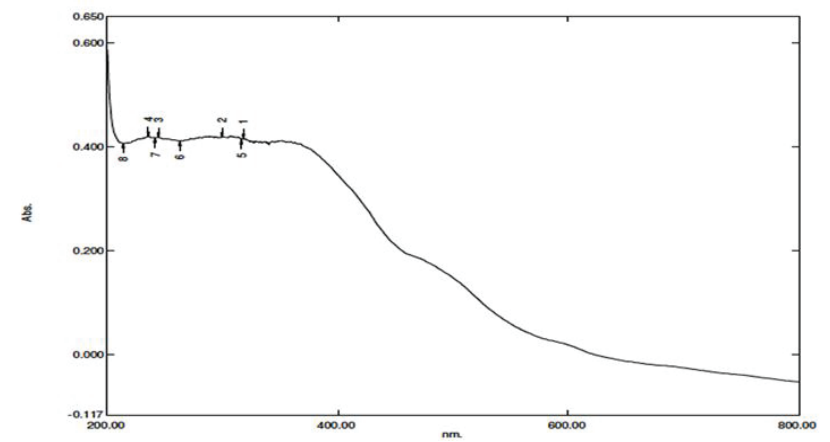

Fig. 2: UV absorption of synthesized iron nano particles from Pleurotus florida

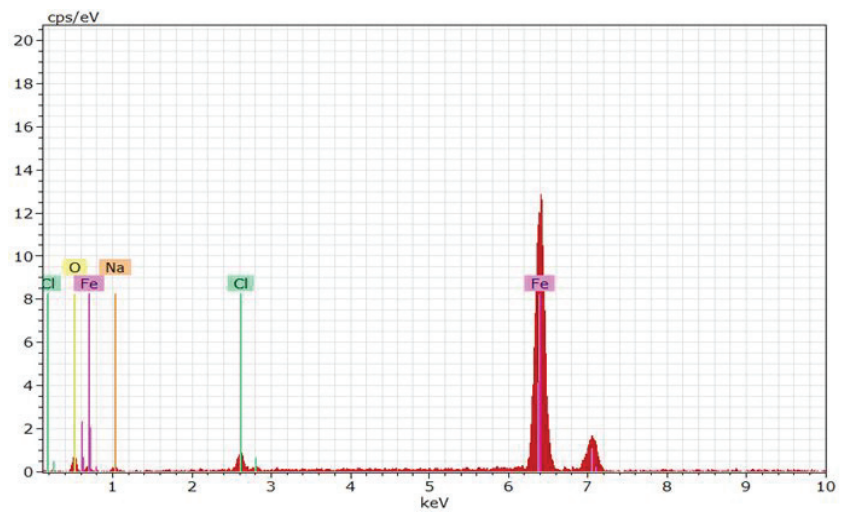

Fig. 3: The energy dispersive X-ray analysis (EDX) of synthesized iron nanoparticles of Pleurotus florida 
glabrata $(20 \pm 1.57 \mathrm{~mm})$ and lower activity was found in Staphylococcus aureus $(16 \pm 1.50 \mathrm{~mm})$. The zone of inhibitions was ranging from $20-24 \mathrm{~mm}$ diameter in $200 \mu \mathrm{g} / \mathrm{ml}$ concentration. The highest zone of inhibitions $(20 \pm 1.57 \mathrm{~mm})$ was noted in Candida glabrata followed by Micrococcus mucilaginosus $(20 \pm 1.13 \mathrm{~mm}), \quad$ Pseudomonas aeruginosa $(19 \pm 0.96 \mathrm{~mm})$, Candida albicans $(19 \pm 0.87 \mathrm{~mm})$, Klebsiella terrigena $(18 \pm 1.39 \mathrm{~mm})$, Escherichia coli

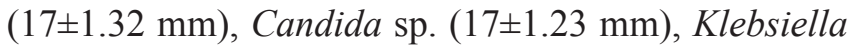
pneumonia $(17 \pm 0.51 \mathrm{~mm})$, Bacillus cereus $(17 \pm 0.37$ $\mathrm{mm})$ and Staphylococcus aureus $(16 \pm 1.50 \mathrm{~mm})$ (Table 2; fig. 4). The iron nanoparticles of $P$. florida showed highest zone of inhibition ranging from 14-17 $\mathrm{mm}$ diameter in $150 \mu \mathrm{g} / \mathrm{ml}$ concentration. The highest zone of inhibitions $(17 \pm 1.93 \mathrm{~mm})$ was noted in Candida glabrata followed by Micrococcus mucilaginosus (17 $\pm 1.29 \mathrm{~mm})$, Pseudomonas aeruginosa $(17 \pm 1.15 \mathrm{~mm})$, Candida albicans $(15 \pm 1.81 \mathrm{~mm})$ Klebsiella terrigena $(15 \pm 1.15 \mathrm{~mm})$ Bacillus cereus $(14 \pm 1.70 \mathrm{~mm})$ Candida sp. $(14 \pm 1.53 \mathrm{~mm})$ Klebsiella pneumoniae $(14 \pm 1.31 \mathrm{~mm})$ Staphylococcus aureus $(14 \pm 0.81 \mathrm{~mm})$ and Escherichia coli $(14 \pm 0.81 \mu \mathrm{mm})$ at $150 \mu \mathrm{g} / \mathrm{ml}$ concentration (Table 2; fig. 4).

The iron nanoparticles extract $(100 \mu \mathrm{g} / \mathrm{ml})$ of $P$. florida showed higher zone of inhibition against Pseudomonas aeruginosa $(14 \pm 1.67 \mathrm{~mm})$ followed by Candida glabrata $(14 \pm 0.31 \mathrm{~mm})$, Candida albicans $(13 \pm 1.97 \mathrm{~mm})$, Micrococcus mucilaginosus $(13 \pm 0.76 \mathrm{~mm})$, Staphylococcus aureus (12 $\pm 1.73 \mathrm{~mm})$, Klebsiella terrigena $(12 \pm 1.43 \mathrm{~mm})$, Candida sp. (12 $\pm 1.31 \mathrm{~mm})$, Bacillus cereus $(12 \pm 0.96 \mathrm{~mm})$, Escherichia coli $(12 \pm 0.57 \mathrm{~mm})$ and Klebsiella pneumoniae (11 $\pm 0.31 \mathrm{~mm})$ (Table 2; fig. 4).

Among these three concentrations $(100 \mu \mathrm{g} / \mathrm{ml}, 150 \mu \mathrm{g} / \mathrm{ml}$ and $200 \mu \mathrm{g} / \mathrm{ml}$ ) of iron nanoparticles, the higher concentration $(200 \mu \mathrm{g} / \mathrm{ml})$ showed higher inhibitory activity against all the tested microorganisms. The negative control of Ferric chloride had lower effect (5-7 $\mathrm{mm})$ on microbial growth whereas the positive control (Amphicillin) has showed a strong inhibition of selected microorganisms in the ranging from 20-21 $\mathrm{mm}$ diameter in $100 \mu \mathrm{g} / \mathrm{ml}$ concentration. Interestingly, the lower concentration $(100-150 \mu \mathrm{g} / \mathrm{ml})$

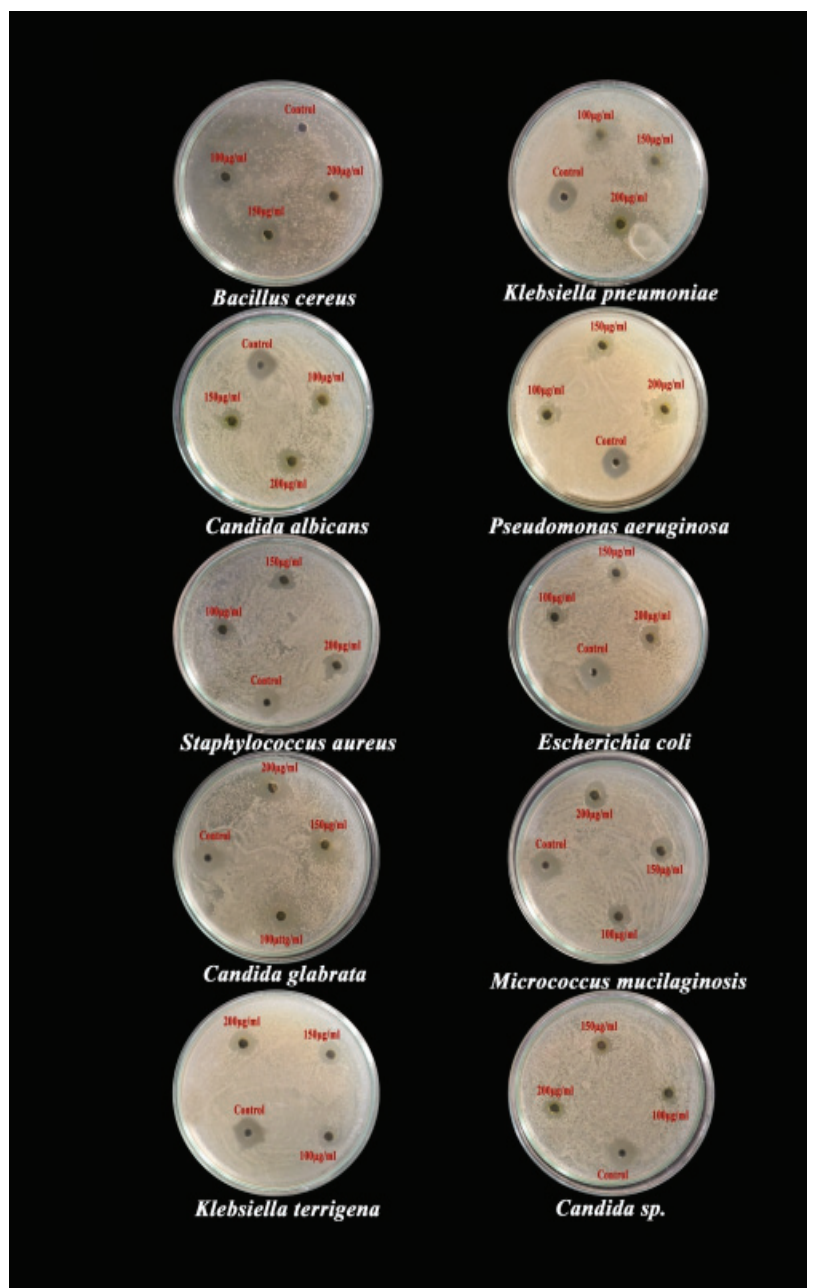

Fig. 4: Antimicrobial activity of iron nanoparticles Pleurotus florida of against human pathogens

\section{TABLE 2: EFFECT OF IRON NANOPARTICLES OF PLEUROTUS FLORIDA ON ZONE OF INHIBITION AGAINST SELECTED PATHOGENIC MICROORGANISM}

\begin{tabular}{|c|c|c|c|c|c|c|}
\hline \multirow{2}{*}{ S.No } & \multirow{2}{*}{ Name of the microbial strains } & \multicolumn{5}{|c|}{ Zone of inhibition(mm) } \\
\hline & & $100 \mu \mathrm{g} / \mathrm{ml}$ & $150 \mu \mathrm{g} / \mathrm{ml}$ & $200 \mu \mathrm{g} / \mathrm{ml}$ & Control $\left(\mathrm{FeCl}_{3}\right)$ & Ampicillin $100 \mu \mathrm{g} / \mathrm{ml}$ \\
\hline 1 & Bacillus cereus & $12 \pm 0.96$ & $14 \pm 1.70$ & $17 \pm 0.37$ & $8 \pm 1.21$ & $20 \pm 0.95$ \\
\hline 2 & Staphylococcus aureus & $12 \pm 1.73$ & $14 \pm 0.81$ & $16 \pm 1.50$ & $7 \pm 1.03$ & $20 \pm 0.57$ \\
\hline 3 & Klebsiella pneumoniae & $11 \pm 0.31$ & $14 \pm 1.31$ & $17 \pm 0.51$ & $8 \pm 1.72$ & $21 \pm 0.50$ \\
\hline 4 & Micrococcus mucilaginosus & $13 \pm 0.76$ & $17 \pm 1.29$ & $20 \pm 1.13$ & $8 \pm 0.98$ & $21 \pm 0.81$ \\
\hline 5 & Pseudomonas aeruginosa & $14 \pm 1.67$ & $17 \pm 1.15$ & $19 \pm 0.96$ & $10 \pm 1.35$ & $21 \pm 0.95$ \\
\hline 6 & Escherichia coli & $12 \pm 0.57$ & $14 \pm 0.81$ & $17 \pm 1.32$ & $9 \pm 1.85$ & $21 \pm 0.81$ \\
\hline 7 & Klebsiella terrigena & $12 \pm 1.43$ & $15 \pm 1.15$ & $18 \pm 1.39$ & $8 \pm 1.13$ & $21 \pm 0.81$ \\
\hline 8 & Candida albicans & $13 \pm 1.97$ & $15 \pm 1.81$ & $19 \pm 0.87$ & $9 \pm 0.87$ & $21 \pm 0.57$ \\
\hline 9 & Candida glabrata & $14 \pm 0.31$ & $17 \pm 1.93$ & $20 \pm 1.57$ & $7 \pm 1.31$ & $21 \pm 1.50$ \\
\hline 10 & Candida sp. & $12 \pm 1.31$ & $14 \pm 1.53$ & $17 \pm 1.23$ & $8 \pm 1.74$ & $20 \pm 1.29$ \\
\hline
\end{tabular}

t-standard error 
of iron nanoparticles extract of mushroom were equally worked against the pathogenic microorganism more than that of standard antibiotic (Ampicillin) used. Generally, Ampicillin at $100 \mu \mathrm{g} / \mathrm{ml}$ alone inhibiting the pathogenic fungi at the range of $20-21 \mathrm{~mm}$, whereas, the lower concentration of $(100-150 \mu \mathrm{g} / \mathrm{ml})$ iron nanoparticles extract equally responded against pathogenic microbes.

Nanoparticles have many effects on human health relative to bulk material from which they are produced $^{[16]}$. The increase in the biological activity of nanoparticles can be beneficial, detrimental or both and nanoparticles are generally small enough to have an access to skin, lungs, and brain ${ }^{[17]}$. Chemical synthesis methods lead to presence of some toxic chemicals absorbed on the surface that may have adverse effect in the medical application. Biological synthesis provides advancement over the chemical and physical method as it is coast effective, environmental friendly, easily scaled for large scale synthesis and no need to use high pressure, energy, temperature and toxic chemicals. Moreover, the utilization of biological systems through nanoparticles synthesis is a notable alternative in advanced multifaceted approaches.

In previous research, most of the researchers have focused the synthesis of nanoparticles from mushroom extract with silver and no works have been attempted by iron particles. It is a first attempt to study the synthesis of iron nanoparticles from extract of P. florida. Pleurotus florida extract was used for synthesis of iron nanoparticles in different ratio of Ferric chloride solutions and different ratio of mushroom extracts were added into Ferric chloride solution (1:1 ratio). It has turned from brown to dark brown colour which indicated the formation of iron nanoparticles. The development of dark brown colour of the nanoparticles is due to the surface plasmon resonance (SPR) exhibited by nanoparticles. The iron nanoparticles were spherical with increased productivity as shown by sharp and intense surface Plasmon resonance bonds for the nanoparticles prepared using an excess of the extract. The synthesized iron nanoparticles were characterized by UV-VIS Spectroscopy which has proved to be very useful for the analysis of nanoparticles. The intensity of peak with respect to the height, increased gradually with increase of time. It was observed from the spectra that the iron surface plasma band occurs at $270 \mathrm{~nm}$.

The morphology and the particle size of iron free were determined by using SEM. The Synthesized nanoparticles were spherical in size and roughly with $100 \mathrm{~nm}$. Similar yields and shape of silver nanoparticles were reported in earlier studies of Jaidev and Narasimha ${ }^{[18]}$ with Agaricus bisporus and P. florida mushrooms. The EDX has revealed strong signal in maximum percentage $(87.57 \%)$ of iron $(\mathrm{Fe})$ region which was found in synthesized powder sample and it was confirmed with the formation of iron nanoparticles. The other peak for Chlorine (2.42\%), Sodium (3.20\%) and Oxygen $(6.81 \%)$ in Fe has due to the precursors of iron nanoparticles.

In the present study, the iron nanoparticles synthesized by using mushroom extracts were tested for antimicrobial activity by agar well-diffusion method against various pathogenic Gram-positive bacteria, gram-negative bacteria and Fungi. The iron nanoparticles of $P$. florida showed strong inhibition against Candida glabrata and lower activity was found in Staphylococcus aureus. To determine the antibacterial activity of silver nanoparticles, against bacterial strains such as E.coli, Staphylococcus sp., Pseudomonas sp., and Bacillus sp., the cultures were grown overnight in nutrient broth on a rotary shakers $(200 \mathrm{rpm})$ at $37^{\circ}$ and inoculated into nutrients agar plates. Different concentrations $(10 \mu 1,50 \mu 1,100 \mu 1)$ of sample were poured to the agar wells. The plates were incubated at $37^{\circ}$ for $24 \mathrm{~h}$. After the period of incubation, zone of inhibition around the wells were measured ${ }^{[19]}$.

Smania et al. ${ }^{[20,21]}$ proved that this mushroom produces cinnabarine, an orange pigment active against Bacillus cereus, Staphylococcus aureus, Leuconostoc mesenteroides, Lactobacillus plantarum and several Streptococcus spp. Cinnabarine was more active against gram-positive than gram-negative bacteria ${ }^{[22]}$.

Ozen et al. ${ }^{[23]}$ and Tambeker et al. ${ }^{[24]}$ reported positive report against Escherichia coli, but also against Pseudomonas aeruginosa, Enterobacter aerogenes, Klebsiella pneumoniae, Proteus vulgaris, Salmonella typhi and Salmonella typhimurium. However, these divergences may be due to different methods and concentrations used. The methanolic extracts of Agaricus bitorquis were effective against three of gram negative bacteria namely Yersinia enterocolitica, Klebsiella pneumoniae and Proteus vulgaris. A. essettei, A. silvicola, A. silvaticus and A. nigrecentulus were not showed any antibacterial activity against gram negative bacteria ${ }^{[25]}$.

It is a first attempt on synthesize of iron nanoparticles by using mushroom extract. The production of iron nanoparticles from Pleurotus florida was initially confirmed by color changes from brown to dark brown and 
were further characterized by UV-VIS spectroscopy and SEM. The biosynthesized iron nanoparticles showed higher zone of inhibition against Candida glabrata followed by Micrococcus mucilaginosus, Pseudomonas aeruginosa, Candida albicans, Klebsiella terrigena, Escherichia coli, Candida sp., Klebsiella pneumoniae, Bacillus cereus and Staphylococcus aureus. This extract was effectively tested against microorganisms which was well comparable with standard antibiotics. The present study has recommended iron nanoparticles from mushrooms have great potential to act as safe alternative to antibiotics to fight the challenges of drug discovery.

\section{REFERENCES}

1. Gericke M, Pinches A. Biological synthesis of metal nanoparticles. Hydrometallurgy 2006;83(1-4):132-40.

2. Glomm RW. Functionalized nanoparticles for application in bionanotechnology. J Dispers Sci Technol 2005;26(3):389-14.

3. Chan WCW. Bio nanotechnology progress and advances. Biol Blood Marrow Tr 2006;12:87-91.

4. Boisselier E, Astruc D. Gold nanoparticles in nanomedicine: preparation, imaging, diagnostics, therapies and toxicity. Chem Soc Rev 2009;38(6):1759-82.

5. Ahmad A, Mukherjee P, Senapati S, Mandal D, Khan ML, Kumar R, et al. Extracellular biosynthesis of silver nanoparticles using the fungus Fusarium oxysporum. Colloids and Surfaces B: Biointerfaces 2003;28:313-8.

6. Zhang XG, Peng YN, Li XR, Ma GD, Chen XQ. Screening of iron-enriched fungus from natural environment and evaluation of organically bound iron bioavailability in rats. Food Sci Technol 2015;35(1):58-65.

7. Iravani R. Green synthesis of metal nanoparticles using plants. Green Chemistry 2011;13:2638-50.

8. Sun LW, Jiang ZJ, Liu CY. Catalytic Properties of Silver Nanoparticles Supported on Silica Spheres. J Phys Chem 2005;109(5):1730-5.

9. Mahdavi M, Namvar F, Ahmad MB, Mohamad R. Green biosynthesis and characterization of magnetic iron oxide (Fe3O4) nanoparticles using seaweed (Sargassum muticum) aqueous extract. Molecules 2013;18(5):5954-64.

10. Lee C, Kim JY, Lee WI, Nelson KL, Yoon J, Sedlak DL. Bactericidal effect of zero-valent iron nanoparticles on Escherichia coli. Environ Sci Technol 2008;42(13):4927-33.

11. Chang ST, Buswell JA. Mushroom Nutriceuticals. World J Microbiol Biotechnol 1996;12:473-6.

12. Ajith TA, Janardhanan KK. Indian medicinal mushrooms as a source of antioxidant and antitumoragents. J Clinl Biochem Nutr 2007;40:157-62.

13. Manikandan G, Ramasubbu R. Antimicrobial Activity of Leaf Extracts of Memecylon heyneanum Benth. ex Wight \& Arn.: An Endemic Tree Species of Southern Western Ghats. Adv Zool Bot 2020;8(3):258-268.

14. Packiyalakshmi D, Athilakshmi P, Gayathri S, Karthiga P, ThiriBhuvaneswari R, Manikandan G. Antimicrobial potential of different solvents leaf extract of Millettia peguensis against selected pathogens. Pharma Innovat J 2017;6(10):119-24.

15. Ramasubbu R, Manikandan G, Sasi Kala N. Phytochemical composition and antimicrobial properties of leaf essential oil of Garcinia imberti Bourd and G. travancorica Bedd. Int J Adv Sci Technol 2020;29(2):1082-92.

16. Albrecht MA, Evans CW, Raston CL. Green chemistry and the health implications of nanoparticles. Green Chemistry 2006;8:417-432.

17. Koziara JM, Lockman PR, Allen DD, Mumper RJ. In situ blood-brain barrier transport of nanoparticles. Pharma Res 2003;20:1772-78.

18. Jaidev LR, Narasimha G. Fungal mediated biosynthesis of silver nanoparticles, characterization and antimicrobial activity. Biointerfaces 2010;81:430-3.

19. Narasimha G, Praveen Mallikarjuna K, Deva Prasad Raju. Mushrooms (Agaricusbisporus) mediated biosynthesis of sliver nanoparticles, characterization and their antimicrobial activity. Int J Nano Dimens 2011;2(1):29-36.

20. Smania A, Monache FD, Smânia EFA, Gil ML, Benchetrit LC, Cruz F. Antibacterial activity of a substance produced by the fungus Pycnoporus sanguineus (Fr.) Murr. J Ethnopharmacol 1995;45:177-81.

21. Smania EFA, Smania A, Loguercio-Leite C, Gil ML. Optimal parameters for cinnabarin synthesis by Pycnoporus sanguineus. J Chem Technol Biotechnol 1997;70:57-9.

22. Rosa LH, Machado KMG, Jacob CC, Capelari M, Rosa CA, Zani CL. Screening of Brazilian Basidiomycetes for antimicrobial activity. Mem do Inst Oswaldo Cruz 2003;98:967-74.

23. Ozen T, Darcan C, Aktop O, Turkekul I. Screening of antioxidant, antimicrobial activities and chemical contents of edible mushrooms wildly grown in the Black Sea region of Turkey. Comb Chem High T Scr 2011;14:72-84.

24. Tambekar DH, Sonar TP, Khodke MV, Khante BS. The Novel antibacterials from two edible mushrooms: Agaricus bisporus and Pleurotus sajor caju. Int J Pharmacol 2006;2:584-7.

25. Ozturk M, Duru ME, Kivrak S, Mercan-Dogan N, Turkoglu A, Ozler MA. In vitro antioxidant, anticholinesterase and antimicrobial activity studies on three Agaricus species with fatty acid compositions and iron contents: A comparative study on the three most edible mushrooms. Food Chem Toxicol 2011;49:1353-60. 